\title{
Effect of oral L- arginine versus intravenous hydration on maternal and fetal outcome in idiopathic oligohydramnios
}

\author{
Suhail Iqbal $^{1 *}$, Mehak Ayub Malik ${ }^{1}$, Heena Kaurani², Divya Chauhan³
}

\begin{abstract}
${ }^{1}$ Department of Obstetrics and Gynaecology, Government Medical College, Baramulla. Jammu and Kashmir, India ${ }^{2}$ Department of Obstetrics and Gynaecology, Dr Sampurnanand Medical college, Jodhpur, Rajasthan, India ${ }^{3}$ Department of Obstetrics and Gynaecology, University College of Medical Sciences and Guru Teg Bahadur Hospital, Delhi, India
\end{abstract}

Received: 22 February 2021

Accepted: 01 April 2021

\section{*Correspondence:}

Dr. Suhail Iqbal,

E-mail: isuhaillove@gmail.com

Copyright: (C) the author(s), publisher and licensee Medip Academy. This is an open-access article distributed under the terms of the Creative Commons Attribution Non-Commercial License, which permits unrestricted noncommercial use, distribution, and reproduction in any medium, provided the original work is properly cited.

\section{ABSTRACT}

Background: Adequate amount of amniotic fluid was required for normal growth of fetus. Oligohydramnios or reduced amount of amniotic fluid is associated with adverse maternal and perinatal outcome due to increase in induced labour and operative deliveries. Idiopathic oligohydramnios is a condition in which no other risk factors are associated with pregnancy. This study was done to compare the effect of L-arginine and IV hydration on improvement of amniotic fluid index and fetal growth.

Methods: Total 50 patients were included in the study according to inclusion criteria and divided equally into two groups randomly. IV hydration was given to one group and other group received L- arginine sachet orally. The effect on AFI and fetal outcome was compared.

Result: The result was compared with respect to age, gravidity, gestational age and AFI at the time of study and after giving treatment. Maternal and fetal outcome was compared which shows that L-arginine was more effective in increasing the AFI and thereby leading to favorable results in the form of increase in gestational age at time of delivery and fetal weight.

Conclusion: This study shows that both IV hydration and L-arginine are useful in treatment of oligohydramnios. But L-arginine appears more advantageous over IV hydration in improving pregnancy outcome and reducing perinatal morbidity and mortality.

Keywords: Amniotic fluid index, Fetal outcome, L-arginine, Oligohydramnios, IV hydration

\section{INTRODUCTION}

Amniotic fluid surrounds the developing fetus in amniotic sac. It is one of the essential requirements for appropriate fetal growth and good fetal outcome. ${ }^{1}$ The amniotic fluid contains nutrients and growth factors that facilitates fetal growth, provides mechanical cushioning and antimicrobial effect that protects the fetus and allows assessment of fetal maturity and disease. ${ }^{2}$

The mechanism of amniotic fluid production, composition and volume depends on the gestational age. ${ }^{3}$ Amniotic fluid increases progressively to about a liter between 32 and 34 weeks but decreases thereafter till the term around $400 \mathrm{ml}$. Oligohydramnios is a condition in which the amount of amniotic fluid is decreased abnormally. It complicates approximately 1 to $2 \%$ abnormally. ${ }^{4}$ The quantitative assessment of amniotic fluid is done by ultrasound using Amniotic fluid index (AFI) or single largest vertical pocket.

AFI between 8-24 is considered normal, between 5 and 8 is borderline and less than 5 is oligohydramnios. Oligohydramnios can be presented as isolated abnormality in an uncomplicated pregnancy or can be associated with complicated pregnancy. Various maternal 
and fetal factors are responsible for oligohydramnios are : Congenital anomalies, chromosomal abnormalities, urinary tract obstruction, bilateral renal agenesis, premature rupture of membranes, post term pregnancy, uteroplacental insufficiency, Diabetes mellitus, Pregnancy induced hypertension, drugs like ACE and PG synthesis inhibiters, twin to twin transfusion syndrome and twin reversal arterial perfusion (TRAP).

Early onset oligohydramnios is associated with compression of fetal organs resulting in birth defects, pulmonary hypoplasia, increased risk of abortion or still birth. In late pregnancy, it is associated with IUGR, preterm birth and fetal demise. During labour it can cause cord compression, meconium-stained liquor, abnormal fetal heart rate, increased chances of operative interventions, low APGAR score, ICU admission and neonatal death. ${ }^{5}$ There is strong correlation between maternal plasma volume and amniotic fluid volume. ${ }^{6}$ Hydration status and maternal plasma osmolality can also alter amniotic fluid volume. ${ }^{7}$ So I.V. hydration therapy is used to improve maternal hydration for treatment of oligohydramnios since a long period.

Amnioinfusion is also an option but it is invasive procedure and there is an inherent risk of fetal loss. ${ }^{8}$ Now a days, L- arginine is used in the treatment of oligohydramnios which is also useful in cases of IUGR. L-arginine is a semi essential amino acid and sole endogenous precursor of nitric oxide (NO). ${ }^{9}$ It is involved in the regulation of blood flow in vessels. L-arginine promotes the intrauterine growth of the fetus by increasing the bioavailability of endothelial NO production and improving the umbilical artery flow. This study was conducted to compare the effect of oral hydration therapy by L- arginine versus I.V. hydration therapy on AFI in patients with oligohydramnios.

\section{METHODS}

This was a prospective interventional study done in the Department of Obstetrics and Gynecology, Shrimati Heera Kunwar Ba Hospital, Jhalawar Medical College, Jhalawar for a period of one year from March 2018 to February 2019 after getting approval from the institutional research ethics committee. 50 cases were selected for the study after taking detailed history of present pregnancy and past obstetrical and medical history.

\section{Inclusion criteria}

Patient giving consent for the study, singleton pregnancy with 28 to 34 weeks of gestation, presence of intact membranes, $\mathrm{AFI}<8 \mathrm{~cm}$, patients without true labour pains

\section{Exclusion criteria}

Patients not giving consent for the study, multifetal pregnancy, gestational age less than 24 weeks and more than 34 completed weeks, preterm premature rupture of membranes, associated fetal malformations, IUGR, severe anemia, Hypertensive disorder of pregnancy, chronic hypertension, chronic renal disease, heart disease, Diabetes mellitus, or any associated medical disorder, threatened preterm labour, history of smoking or any other addiction, history of having received treatment for oligohydramnios. The patients fulfilling the inclusion criteria were admitted. Thorough history was taken and complete clinical examination was done. Routine blood and urine investigations were done. For all the women, ultrasound examination was done. AFI was measured by using the four-quadrant technique.All the readings were taken by the same sonographer who was blinded for the study to minimize any interobserver variation. A baseline color doppler study was done to rule out fetal growth restriction. Study group was divided randomly into two groups each having 25 patients. One group (Group 1) received intravenous hydration drip of normal saline (500ml.) for 7 days (1drip/day) and other group (Group 2) was given L-arginine 3 gram per sachet in oral form twice a day. AFI was measured at the end of 7 days and 1 week after the treatment. Additional drips and oral Larginine sachet were given if necessary, as per AFI until 36 weeks of pregnancy. Patients were discharged after improvement of AFI and advised for proper diet and adequate oral hydration. Weekly follow up was done and serial ultrasound was done at regular intervals till delivery.

All the patients were monitored for hemodynamic changes. Serial non stress test and biophysical profile was done till delivery. Mean increase in AFI, therapy to delivery interval and neonatal outcome was noted in this study. Data was analyzed and statistical comparisons were made by using Chi square test. The difference was considered significant if $\mathrm{P}$-value was $<0.05$.

\section{Statistical analysis}

Data were analyzed using SPSS software version 18.0 for windows.

\section{RESULTS}

Table 1: Maternal characteristics.

\begin{tabular}{|lll|}
\hline $\begin{array}{l}\text { Characteristic } \\
\text { Mean maternal } \\
\text { age (years) }\end{array}$ & $\begin{array}{l}\text { Group 1(IV } \\
\text { hydration) }\end{array}$ & $\begin{array}{l}\text { Group 2 (L- } \\
\text { arginine) }\end{array}$ \\
\hline Gravidity & $\begin{array}{l}\text { Primigravida 14 } \\
\text { Multigravida 11 }\end{array}$ & $\begin{array}{l}\text { Primigravida 16 } \\
\text { Multigravida 9 }\end{array}$ \\
\hline $\begin{array}{l}\text { Mean } \\
\text { gestational age } \\
\text { (weeks) }\end{array}$ & $30.9 \pm 1.54$ & $30.66 \pm 1.61$ \\
\hline $\begin{array}{l}\text { Mean AFI } \\
\text { before } \\
\text { intervention }\end{array}$ & $6.53 \pm 0.79$ & $6.57 \pm 0.79$ \\
\hline
\end{tabular}


Table 2 shows that mean AI after 7 days of treatment in IV hydration group was $(7.46 \pm 0.88) \mathrm{cm}$. and in $\mathrm{L}$ arginine group was $(8.74 \pm 1.15 \mathrm{~cm})$., this shows that mean increase in AFI in L- arginine group was significantly higher than IV hydration group.(P- value $0.0005)$.

Table 2: Changes in AFI after 7 days of therapeutic intervention.

\begin{tabular}{|llll|}
\hline & Group 1 (IV hydration) & Group 2 (L-arginine) & P value \\
\hline Mean AFI before intervention & $6.53 \pm 0.79$ & $6.57 \pm 0.79$ & 0.441 \\
\hline Mean AFI after intervention & $7.46 \pm 0.88$ & $8.74 \pm 1.15$ & 0.0005 \\
\hline Mean increase in AFI & 0.98 & 1.55 & \\
\hline
\end{tabular}

Table 3: Requirement of repeat intervention in both groups.

\begin{tabular}{|llll|}
\hline Repeat intervention & Group1 (IV hydration) & Group 2 (L-arginine) & P value \\
\hline Required & 15 & 9 & 0.085 \\
\hline Not required & 10 & 16 & 0.006 \\
\hline
\end{tabular}

Table 4: Maternal outcome.

\begin{tabular}{|llll|}
\hline $\begin{array}{l}\text { Mean gestational age at time of } \\
\text { delivery (weeks) }\end{array}$ & Group 1 (IV hydration) & Group 2 (L-arginine) & P value \\
\hline $\begin{array}{l}\text { Mean increase in gestational age } \\
\text { at time of delivery (weeks) }\end{array}$ & $3.588 \pm 1.42$ & $36.59 \pm 1.69$ & \\
\hline Mode of delivery & 17 & 5.0001 & \\
\hline Vaginal & 8 & 18 & 0.76 \\
\hline LSCS & & 7 & \\
\hline
\end{tabular}

Table 5: Neonatal outcome.

\begin{tabular}{|llll|}
\hline & Group 1 (IV hydration) & Group 2 (L-arginine) & P value \\
\hline $\begin{array}{l}\text { Mean fetal wt. before } \\
\text { intervention(kg) }\end{array}$ & $1.20 \pm 0.12$ & $1.29 \pm 0.24$ & 0.100 \\
\hline $\begin{array}{l}\text { Mean fetal wt. at time of } \\
\text { delivery (kg) }\end{array}$ & $1.84 \pm 0.37$ & $2.36 \pm 0.25$ & 0.29 \\
\hline Mean increase in fetal wt. & 0.64 & 1.07 & \\
\hline NICU admission & 12 & 4 & 0 \\
\hline Neonatal death & 0 & & \\
\hline
\end{tabular}

Table 3 shows the requirement of repeat treatment in both the groups. Table 4 shows that mean gestational age at the time of delivery was greater in L-arginine group as compared to IV hydration group. There was a significant increase in gestational age by 5.93 weeks. (P-value $0.0001)$ There was no significant difference in mode of delivery in both the groups.

Table 5 shows that mean increase in the fetal weight was significantly higher in L-arginine group. Neonatal outcome was better in L- arginine group. There was no neonatal death in both the groups.

\section{DISCUSSION}

Amniotic fluid has multiple functions. It provides nutritive fluid medium for the development of fetus. It protects fetus from concussion, pressure and desiccation.
For normal growth of the fetus, adequate amount of amniotic fluid is required. It cushions against all sorts of trauma and agitations. It works as a primary source of fetal nutrients and its bacteriostatic properties prevents the fetus from infection.

Oligohydramnios is associated with increased risk of adverse perinatal outcome. Reduced amount of amniotic fluid in labour is associated with umbilical cord compression and fetal hypoxia. The decrease in amniotic fluid volume is responsible for increased rate of labour induction, meconium aspiration syndrome, nonreassuring fetal heart rate, intra uterine and neonatal death and also still birth.

Oligohydramnios is being detected more often these days due to routinely performed obstetric ultrasound. Isolated oligohydramnios refers to absence of any significant 
growth restriction, normal umbilical artery doppler velocimetry and failure to identify a recognizable underlying etiology. ${ }^{10}$

Various medical and surgical interventions have been tried for treatment of oligohydramnios. It is well known that maternal hydration helps to improve the placental fluid transfer. Amniotic forces are responsible for water transfer between mother and fetus. Net transplacental water exchange is determined by electrolyte gradient. It was shown in a study that maternal fluid overloading causes reduction in maternal fetal osmotic gradient which facilitate water transfer to fetus, so fetal urine production increases.

Nitic oxide (NO) plays an important role in placental vascular endothelial function. It regulates placental perfusion. NO is synthesized from L- arginine. NO diffuses into vascular smooth muscle cells and causes vasodilatation. Vasodilatation in renal vessels induced by NO may improve Glomerular Filtration Rate (GFR) and increases fetal urine production.

In our study there was no statistical difference in both the groups according to age, gravidity and gestational age of patients. In this study, mean age in Group 1 was $(23.56 \pm$ 2.48) years and in Group 2 was $(23.6 \pm 2.75)$ years. Most of the women were primigravida in the both groups. These findings were similar to study conducted by Prabha S. et al. Mean gestational age in Group 1 was $30.9 \pm 1.54$ weeks and in Group 2 was $30.66 \pm 1.61$ weeks. In a study conducted by Hebber et al. mean gestational age was $33.4+/-1.9$ weeks. ${ }^{11,12}$ The mean AFI in Group 1 was $6.53 \pm 0.79 \mathrm{~cm}$. and in Group 2 was $6.57 \pm 0.79 \mathrm{~cm}$. In a study by Prabha $\mathrm{S}$ et al. mean AFI in study group was $5.782+/-1.0895 \mathrm{~cm}$. and in study by Hebber et al. mean AFI was $6.9+/-1.7 \mathrm{~cm}$.

The mean increase in the AFI in Group 1(I.V. hydration) was 0.98 and in Group 2 was 1.55 after 7 days of treatment. This shows that mean increase in AFI was more in L- arginine group. In a study conducted by Partelli et al. isotonic solution $(1500 \mathrm{ml})$ was given daily for 7 days in women with AFI less than $5 .{ }^{13}$ The mean AFI in study group was $3.9+/-1.1$ and after 7 days of treatment, it increased to $7.7+/-1.5$. Their study showed that IV hydration can be used as a simple and effective method in treatment of idiopathic oligohydramnios without having any adverse effect on mother and fetus.

In a study by Sreedharan et al. the effect of L-arginine on oligohydramnios between gestational age of 28 and 36 weeks was studied. ${ }^{14}$ they gave sachet of L-arginine (3 $\mathrm{gm})$ to the patients for a period ranging from 1 to 4 weeks. The mean improvement in the AFI was 2.03+/$0.39 \mathrm{~cm}$. which was very significant.

Lamparielloet al. also worked to know the efficacy of Larginine in improvement of fetal growth restrictionand pregnancy outcome and the results were favorable. ${ }^{15}$
In our study, the mean gestational age at the time of delivery was increased in Group $2(36.59 \pm 1.69$ weeks $)$ as compared to Group $1(34.588 \pm 1.42)$ ( $\mathrm{P}$ value $=0.0001)$. The average birth weight was also more and neonatal complications were less in L-arginine group as compared to IV hydration group.

\section{CONCLUSION}

Oligohydramnios is associated with adverse maternal and perinatal outcome. It is very challenging to manage oligohydramnios in pregnant women with gestational age less than 34 weeks. Therapeutic interventions are required to prevent premature induction of labour and to avoid its serious effects on mother and fetus. Like other studies our study has also proved that IV normal saline and L-arginine, both are effective in improvement of oligohydramnios, thereby helps in increase of gestational age at time of delivery and weight gain of fetus. Larginine is more effective than IV normal saline for oligohydramnios correction and fetal growth. Other advantage of L-arginine is that it is safe and does not require hospital admission. Both methods cost effective for treatment of oligohydramnios in developing countries.

\section{ACKNOWLEDGMENTS}

Author acknowledges the role of study participants and timely completion of this study.

\section{Funding: No funding sources} Conflict of interest: None declared

Ethical approval: The study was approved by the Institutional Ethics Committee of Jhalawar Medical College, Jhalawar

\section{REFERENCES}

1. Hebbar S, Rai L, Adiga P. Maternal hydration and Larginine supplementation improves liquor volume in patients with decreased liquor and prolongs pregnancy. Medical J Dr. DY Patil University. 2014;7(4):429.

2. Kumar P, Kakade AS, Mehendale S. Efficacy of intravenous hydration drip versus amino acid drip in idiopathic oligohydramnios. Int J Reprod Contracept Obstet Gynecol. 2016;5:1488-93.

3. Shree P, Mittal N, Kanti V, Vishwakarma S. Role of intravenous amino acid infusion in cases of oligohydramnios and its effect on amniotic fluid index and fetal weight gain. Int J Reprod Contracept Obstet Gynecol. 2016;5:2804-9.

4. Gary Cunningham F. Disorders of Amniotic fluid. 24th Ed. Williams obstetrics. 2014;236-8.

5. Chauhan NS, Namdeo P, Modi JN. Evidence Based Management of Oligohydramnios. J Gynecol. 2018;3(3):2-7.

6. Fernando A. Practical guide to high risk pregnancy and delivery. 2nd Ed. Mosby-year Book. 1993;1509. 
7. Shahnazi M, Meli MS, Hamoony F, Sadrimehr F, Samani FG, Koshavar H. The effects of intravenous hydration on amniotic fluid volume and pregnancy outcomes in women with term pregnancy and oligohydramnios: a randomized clinical trial.J Caring Sci. 2012;1(3):123-8.

8. Sreedharan R, Jajoo S. Effect of L-arginine on amniotic fluid index in oligohydramnios. Int $\mathrm{J}$ Reprod Contracept Obstet Gynecol. 2013;2:80-2.

9. Soni A, Garg S, Patel K, Patel Z. Role of l-Arginine in Oligohydramnios. J Obstet Gynaecol India. 2016;66(1):279-3.

10. Sherer DM. A review of amniotic fluid dynamics and the enigma of isolated oligohydramnios. Am J Perinatol. 2002;19(5):253-6.

11. Prabha S, Vivekanand A, Sarojini A, Sethi P. The role of amino acid infusion in isolated Oligohydramnios. Perspectives in medical research. 2015;3:1-5.

12. Hebbar S, Rai L, Adiga P. Maternal hydration and Larginine supplementation improves liquor volume in patients with decreased liquor and prolongs pregnancy. Med J DY Patil Univ. 2014;7(4):429-4.

13. Tito SP, Salvatore G, Erich C, Maria GC, Stefania DG, Giuseppe P, et al. Maternal hydration therapy improves the quantity of amniotic fluid and the pregnancy outcome in third-trimester isolated oligohydramnios. A controlled randomized institutional trial. Ultrasound Med. 2012;31(2):2394.

14. Sreedharan R, Jajoo S. Effect of L-arginine on amniotic fluid index in oligohydramnios. Int $\mathrm{J}$ Reprod Contracept Obst Gynecol. 2013;2(1):80-2.

15. Lampariello C, De Blasio A, Merenda A, Graziano E, Michalopoulou A, Bruno P. Use of L-arginine in intrauterine growth retardation (IUGR): Authors' experience. Minerva Ginecol. 1997;49(12):577-81.

Cite this article as: Iqbal S, Malik AM, Kaurani $\mathrm{H}$, Chauhan D. Effect of oral L- arginine versus intravenous hydration on maternal and fetal outcome in idiopathic oligohydramnios. Int J Reprod Contracept Obstet Gynecol 2021;10:1943-7. 